\title{
STABILITY OF INTEGRODIFFERENTIAL SYSTEMS OF NONCONVOLUTION TYPE
}

\author{
S. ELAYDI
}

Abstract. A diagonal dominance criterion for the stability of linear Volterra integrodifferential equations of nonconvolution type is given. An alternative method using Liapunov functionals is also introduced.

Mathematics subject classification (1991): 45J05, 34D20.

Key words and phrases: Diagonal dominance, stability, nonconvolution, Volterra.

\section{REFERENCES}

[1] F. BRAUER, Asymptotic Stability of a Class of Integrodifferential Equations, J. Differential Equations 28 (1978), 180-188.

[2] T. A. BurTon, Stability and Periodic Solutions of Ordinary and Functional Differential Equations, Academic Press, Orlando, (1985).

[3] W. A. Coppel, Stability and Asymptotic Behavior of Differential Equations, D. C. Heath and Company, Boston, 1965

[4] S. ElAYDI, Asymptotic Stability of Linear Systems With Infinite Delay, Functional Differential Equations (Ed. Yoshizawa and Kato), World Scientific (1991), 67-74.

[5] S. ElAYDI AND S. SiVASUNDARAM, A Unified Approach to Stability in Integrodifferential Equations via Liapunov Functions, J. Math. Anal. Appl. 144 (1989), 503-531.

[6] K. Gopalsamy, Stability, Instability, Oscillation and Nonoscillation in Scalar Integrodifferential Systems, Bull. Austral. Math. Soc. 28 (1983), 233-246.

[7] G. S. JoRDAN, Asymptotic Stability of a Class of Integrodifferential Systems, J. Differential Equations 31 (1979), 359-365.

[8] T. KRISZTIN, Uniform Asymptotic Stability of a Class of Integrodifferential Systems, Integral Equations and Appl. 1 (1988), 581-597.

[9] R. K. MiLleR Asymptotic Stability Properties of Linear Volterra Integrodifferential Equations, J. Differential Equations 10 (1971), 485-506. 